\title{
Políticas sobre el Alcohol en los países miembros de la Unión Europea y Noruega, 1950-2000
}

\author{
Österberg, E.; Karlsson, T. \\ National Research and Development Centre for Welfare and Health. Alcohol and Drug Research Group. \\ Enviar correspondencia a: \\ Esa Österberg. Ahtu, Stakes. P.O. Box 220. 00531 Helsinki (Finlandia) \\ Fax:+358-9-39672170. Esa.osterberg@stakes.fi
}

\section{RESUMEN}

A principios de la década de 1950, las medidas de control del alcohol eran muy diferentes entre los países que actualmente integran la Unión Europea. En los países nórdicos, las tasas impositivas sobre las bebidas alcohólicas eran muy altas y su venta estaba rigurosamente controlada. En algunos países mediterráneos, apenas había medidas vigentes que controlaran su consumo y el término "política del alcohol" ni siquiera se conocía.

El presente artículo describe los cambios experimentados en Noruega y en los países que actualmente conforman la Unión Europea desde la década de 1950 hasta el año 2000. Mostrará los cambios tan profundos que se han producido en las medidas de control del alcohol y, a consecuencia de ello, lo parecidas que se han vuelto las políticas del alcohol en todos estos países. Ello ha ocurrido, en cierta medida, porque los países nórdicos se han visto obligados a abandonar su control absoluto de la venta y el suministro de alcohol, renunciando a parte de su monopolio sobre este producto. Por otro lado, aunque los países del sur y del centro de Europa han adoptado más medidas para controlar el consumo de alcohol, no han intentado regular la venta y el suministro de este producto sino moldear su demanda o influir directamente sobre algunos problemas relacionados con él, como, por ejemplo, conducir en estado de embriaguez.

Palabras clave: alcohol, políticas, Unión Europea, revisión, medidas de control, historia.

\section{SUMMARY}

At the beginning of the 1950s alcohol measures were very different among the countries now belonging to the EU. In the Nordic countries alcoholic beverages were very heavily taxed and their physical availability was strictly controlled. In some Mediterranean countries there were hardly any alcohol control measures in force and the term alcoholic policy was not even known.

This article describes changes in alcoholic policies in the present EU countries and Norway from the 1950s to the year 2000. It will be shown that there have been many changes in alcohol control measures. As a consequence alcohol policies have become more similar in the studied countries. This has happened partly because the Nordic countries have been forced to give a part of their control directed on alcohol availability and supply like giving up part of their alcohol monopolies. On the other hand, while Southern and Central European countries have adopted more alcohol control measures, they have not tried to regulate alcohol availability or supply but rather tried to mould alcohol demand or affect directly certain alcohol-related problems like drunk driving.

Key words: Alcohol policy, European Union, Alcohol control measures, Post Second World War period, review.

\section{INTRODUCCIÓN}

$\mathbf{U}$ no de los objetivos del Estudio Comparativo Europeo sobre el Alcohol (ECAS) era describir y analizar, dentro de un marco comparativo y longitudinal, las políticas del alcohol en los diferentes países que actualmente integran la Unión Europea (EU) y en Noruega, países que aquí denominaremos
ECAS. En el subestudio de la política del alcohol del proyecto ECAS, la descripción del alcance, de los contenidos y del rigor de las políticas del alcohol, así como el análisis de su desarrollo, se han realizado tanto a nivel individual, en cada uno de los países ECAS, como a nivel europeo en el período que siguió a la Segunda Guerra Mundial (ver Österberg \& Karlsson, 2001a). De acuerdo con el plan del proyecto ECAS, las políticas del alcohol del presente estudio se 
basaban en unos métodos muy diferentes de prevenir los problemas relacionados con el alcohol, que incluían políticas sobre los precios y los impuestos, regulación de la venta y de la publicidad, política de concesión de licencias, programas educativos e informativos, reglamentación y cumplimiento de unas normas para consumir alcohol en lugares públicos y no conducir en estado de embriaguez (ver Acuerdo SOC $98200073905 F 03$ (98CVVF3-3420-0); Österberg \& Karlsson, 2001b).

Presentaremos, a continuación, nuestras conclusiones sobre las similitudes, diferencias y modas en las políticas del alcohol de los países ECAS durante la segunda mitad del siglo XX. Describiremos, en primer lugar, el alcance y el rigor de las políticas del alcohol en estos países, al principio y al final del período estudiado. Nos ocuparemos, en segundo lugar, de las tendencias que predominan en las distintas áreas de la política del alcohol en los países ECAS y mostraremos la situación de las diferentes medidas de control del alcohol durante el año 2000. Al mismo tiempo, señalaremos los cambios realizados en las medidas de control del alcohol en los países ECAS entre 1950-2000. Para finalizar, haremos un resumen de nuestras conclusiones en términos más amplios y discutiremos la viabilidad de las políticas preventivas del alcohol en los países de nuestro estudio, así como las implicaciones de nuestros resultados en una política del alcohol coordinada y de bajo coste dentro de la Unión Europea.

\section{POLÍTICAS SOBRE EL ALCOHOL EN LOS PAÍSES ECASA PRINCIPIOS DE LA DÉCADA DE 1950}

A principios de la década de 1950, las políticas del alcohol, especialmente las de carácter preventivo, diferían enormemente de unos países ECAS a otros. En los países nórdicos, la venta de las bebidas alcohó- licas estaba rigurosamente controlada; además, estas bebidas pagaban unos impuestos muy elevados. En algunos países mediterráneos, por el contrario, apenas se habían tomado medidas que controlaran su consumo y los impuestos especiales sobre el alcohol eran muy bajos, en comparación con los de los países nórdicos. Al mismo tiempo, las escasas medidas sobre el alcohol que había en los países mediterráneos venían casi siempre motivadas por los intereses industriales y comerciales del estado (Österberg \& Karlsson, 2001 b).

Como parte del análisis, el proyecto ECAS desarrolló una escala para medir el alcance y el rigor de las políticas del alcohol en estos países (Karlsson \& Österberg, 2001a). La escala ECAS se divide en seis subgrupos de control del alcohol, una división muy similar a otra realizada anteriormente para intentar clasificar las políticas del alcohol, retrocediendo al menos hasta los primeros años de la década de 1980 (Karlsson \& Österberg, 2001a, 118). Asimismo, casi todas las preguntas incluidas en la escala ECAS se han recopilado de anteriores escalas (cf. Karlsson \& Österberg, 2001a). Cuando las comparamos, la diferencia más significativa es que la escala ECAS no incluye ninguna pregunta sobre los impuestos del alcohol. El motivo de ello es que, en lugar de transformar primero las tasas impositivas especiales sobre el alcohol en puntos de la escala y compararlas entonces entre los diferentes países, la escala ECAS compara el nivel y la estructura de los impuestos sobre el consumo de alcohol en términos económicos, utilizando una moneda común, en nuestro caso el euro.

El siguiente paso, después de resumir los puntos de la escala, es clasificar los países en función de su control bajo, mediano o elevado del alcohol (ver e.g., Davies \& Walsh, 1983). Siempre resulta, en cierta medida, arbitrario establecer las líneas divisorias. No obstante, cuando se sigue este procedimiento, se observa que, con toda lógica, los países nórdicos, con

FIGURA 1. Alcance y rigor de las políticas del alcohol en los países ECAS, 1950 (máximo 20 puntos)

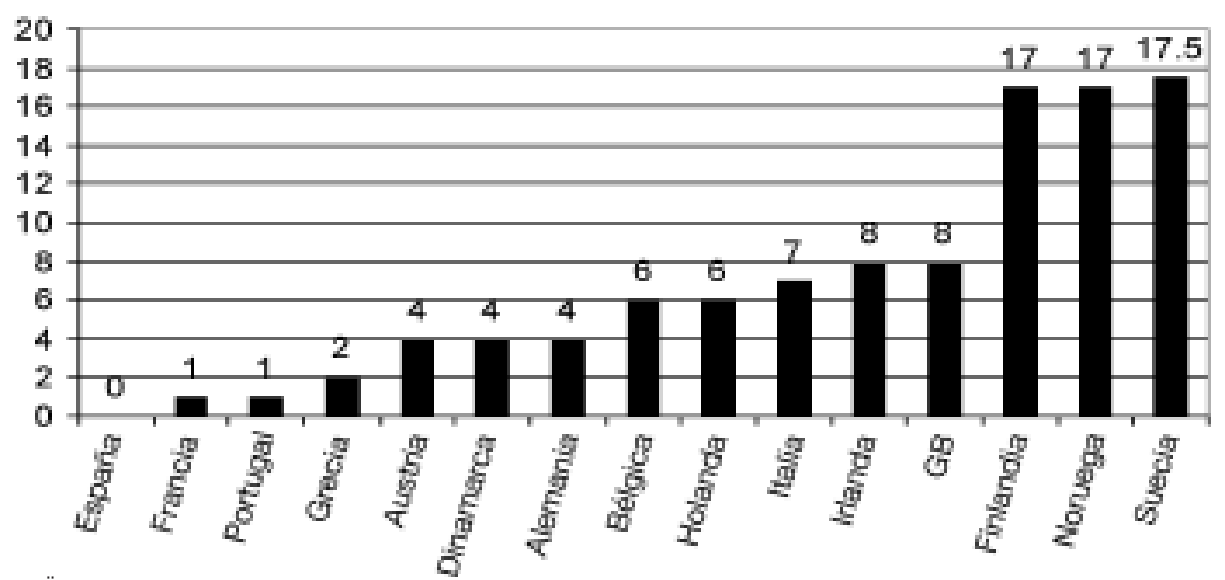

Fuentes: Karlsson \& Österberg, 2001a 


\section{Figura 2. Alcance y rigor de las políticas del alcohol, 2000 (máximo 20 puntos)}

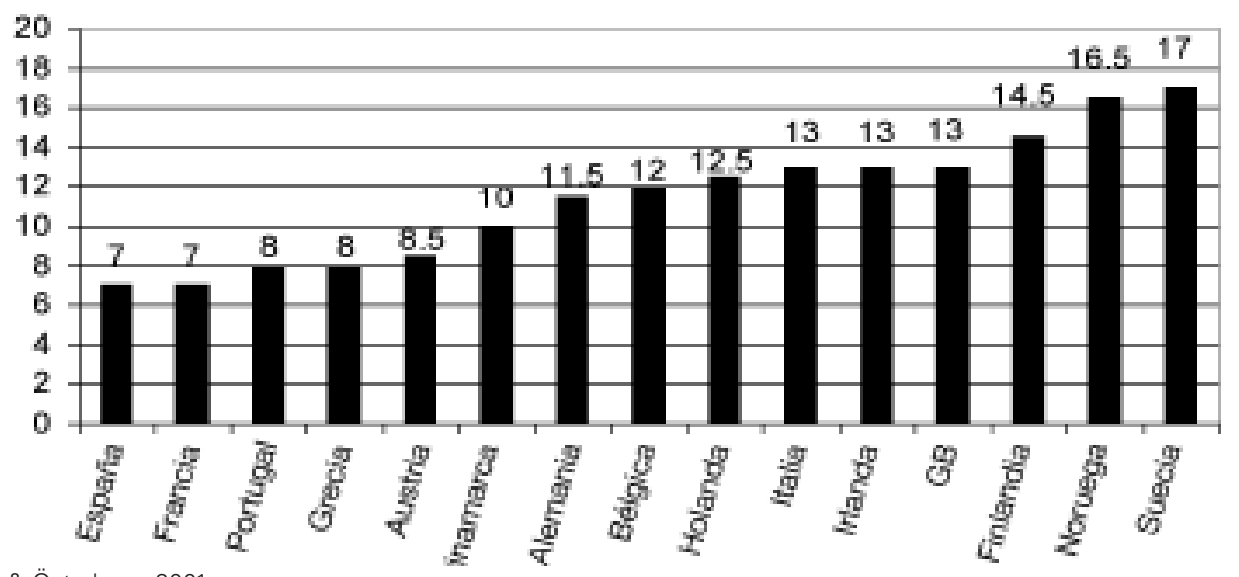

Fuentes: Karlsson \& Österberg, 2001a.

excepción de Dinamarca, estarían clasificados a principios de la década de 1950 como países con un control elevado del alcohol (Figura 1).

Definir Finlandia, Noruega y Suecia como países con un control muy elevado del alcohol a principios de la década de 1950 refleja sin duda la realidad, ya que esos países tenían en aquella época un sistema de monopolio absoluto sobre el alcohol, que incluía el monopolio estatal sobre la producción, la importación, la exportación, la venta al por mayor y la venta al por menor de bebidas alcohólicas para consumir fuera del establecimiento (Karlsson \& Österberg, 2001c; 2001f; 2001i). Además, esos países también controlaban la venta al público de bebidas alcohólicas para consumir en el interior del local, mediante un sistema muy estricto de licencias, y ejercían un control muy estrecho sobre el individuo. En Suecia, por ejemplo, el sistema de racionamiento Bratt seguía vigente, lo que significaba que todos los individuos que deseaban comprar bebidas alcohólicas en uno de los locales que tenían el monopolio de su venta, necesitaba una libreta de racionamiento especial en la que se registraban sus compras. Sólo se podía comprar una cantidad determinada de licor al mes. A las mujeres solteras o a los varones jóvenes les correspondía una cantidad menor que a los varones adultos, y las mujeres casadas no tenían derecho a adquirir nada, pues se suponía que debían compartir las bebidas que se llevaban sus maridos, normalmente cuatro litros de licor al mes (Holder y col., 1998, 82). En Finlandia, no se permitía a las mujeres entrar en un restaurante solas o en grupo, y los hombres tenían que llevar traje y corbata. Además, sólo una parte de la facturación del restaurante podía provenir de la venta de bebidas alcohólicas, por lo que a veces algunos clientes se veían obligados a pedir platos de comida, después de haber tomado unas copas, para que les sirvieran más alcohol. La edad límite para conseguir bebidas alcohólicas también era más elevada en los países nórdicos con monopolio sobre el alcohol que en el resto de los países ECAS, e incluso era más alta que en nuestros días.

Los países que se consideraba ejercían un control mediano sobre el alcohol a principios de la década de 1950 eran Bélgica, Irlanda, Italia, Holanda y el Reino Unido; aunque también Austria, Dinamarca y Alemania podrían incluirse en este grupo (Figura 1). Si el nivel de los impuestos especiales sobre las bebidas alcohólicas estuviera incluido en la escala, Dinamarca estaría sin duda al mismo nivel que Irlanda o el Reino Unido. La razón fundamental para clasificar a los países anteriormente citados como de control medio es su sistema de licencias, así como sus restricciones especiales sobre los establecimientos autorizados a vender bebidas alcohólicas para consumir dentro o fuera del local (ver Allamani y col., 2001; Britton, Karlsson \& Österberg, 2001; Eisenbach-Stangl y col., 2001; Hope y col., 2001; Karlsson \& Österberg, 2001b; 2001 e; Kümmler y col., 2001; Thorsen, Karlsson \& Österberg, 2001). Especialmente en Irlanda y el Reino Unido, las limitaciones en la venta de bebidas alcohólicas para consumir dentro del propio establecimiento eran muy minuciosas y todo el mundo las cumplía. Pero también en Bélgica y en Holanda quedaba algún rastro de sus anteriores medidas de control, muy rigurosas aunque no demasiado respetadas. Por ejemplo, en la década de 1950, según la ley, las bebidas de alta graduación no se servían en los restaurantes belgas, y si uno deseaba comprar bebidas alcohólicas en un establecimiento autorizado para vender alcohol y consumirlo fuera del local la cantidad mínima era de dos litros (Karlsson \& Österberg, 2001b).

El resto de los países, Francia, Grecia, Portugal y España, quedarían definitivamente clasificados como de bajo control sobre el alcohol durante la década de 1950 (ver Gefou-Madianou, Karlsson \& Österberg, 2001; Karlsson \& Österberg, 2001d; 2001 g; 2001 h). Es probable que no sea ninguna sorpresa el hecho de 
que todos los países mediterráneos productores y consumidores de vino, a excepción de Italia, estén encuadrados dentro de este grupo de bajo control.

\section{ALCANCE Y RIGOR DE LAS POLÍTICAS DEL ALCO- HOL EN EL AÑO 2000}

En 1950, la clasificación de los países ECAS en función del alcance y del rigor de sus políticas del alcohol seguía prácticamente la clasificación de los países según sus bebidas preferentes (Bruun y col., $1975,56)$. Todos los países con un control muy elevado eran consumidores de licores. La mayoría de los que tenían un control mediano eran consumidores de cerveza. Las dos excepciones eran Italia, país consumidor de vino, y Holanda, que en aquella época se consideraba aún consumidor de licores (Karlsson \& Simpura, 2001, 85). Todos los países con un control bajo eran consumidores de vino. Al pasar revista a la situación en el año 2000, la clasificación de los países ECAS según la categoría de sus preferencias y el alcance y el rigor de sus políticas del alcohol ha dejado de coincidir (Figura 2). Por otra parte, la clasificación de los países en consumidores de cerveza, vino y licores ha perdido mucho de su significado, puesto que todos los países ECAS antes considerados consumidores de licores ya se habían convertido en consumidores de cerveza en la década de 1990 (Leifman, 2001, 22).

En el año 2000, los tres países nórdicos en los que el alcohol era monopolio estatal seguían constituyendo el núcleo del grupo de elevado control, a pesar de que, a mediados de la década de 1990, habían abandonado su monopolio estatal sobre el alcohol, con excepción del monopolio de la venta de bebidas alcohólicas para consumir fuera del local. Por otra parte, no resulta fácil en nuestros días seguir calificando de monopolios a estas redes estatales de venta de alcohol al público, pues en Finlandia, Noruega y Suecia la venta de cerveza -aunque en diferentes grados- para consumir fuera del local ha dejado de ser o nunca ha sido por completo un monopolio estatal entre 19502000 (ver e.g., Holder y col., 1998).

En el año 2000, Bélgica, Francia, Irlanda, Italia, Holanda, España y el Reino Unido podían ser catalogados como países de control alto o medio del alcohol. Clasificar especialmente a Irlanda y al Reino Unido como países de elevado, más que medio, control del alcohol podría justificarse por el nivel de sus impuestos sobre el consumo, que es claramente más alto que en la media de la Unión Europea (Tabla 1). Ambos países, así como Holanda, poseen también un sistema bastante riguroso de licencias de venta de alcohol al público, lo que responde a las exigencias de su política de salud pública.

La línea divisoria entre los países de control medio y bajo del alcohol es, en cierto modo, arbitraria. En la figura 2, una de las posibilidades sería considerar nueve puntos como la línea divisoria, lo que significaría que Austria, Dinamarca, Alemania, Grecia y Portugal estarían entre los países que ejercen un control bajo sobre el consumo de alcohol. Es fácil percibir que los países de control bajo -aunque la línea divisoria se subiera o bajara de los nueve puntos- no constituyen un grupo demasiado homogéneo. Ni son países mediterráneos o consumidores de vino, ni son centroeuropeos o consumidores de cerveza (Tabla 1).

Los cálculos se basan en los contenidos de alcohol en cerveza, vino y productos intermedios: cerveza $5 \%$

TABLA 1. Impuestos sobre el consumo de bebidas alcohólicas en los países ECAS según categorías de bebida en Julio de 2000, euro por litro de alcohol puro

\begin{tabular}{|c|c|c|c|c|}
\hline País & Bebidas Destiladas & Productos Intermedios & Vino & Cerveza \\
\hline Alemania & 13.04 & 8.52 & 0.00 & 1.97 \\
\hline Austria & 10.03 & 4.04 & 0.00 & 5.21 \\
\hline Bélgica & 16.61 & 5.51 & 4.28 & 4.28 \\
\hline Dinamarca & 36.99 & 7.88 & 8.62 & 9.30 \\
\hline España & 6.85 & 2.55 & 0.00 & 1.68 \\
\hline Finlandia & 50.46 & 39.24 & 21.41 & 28.59 \\
\hline Francia & 14.50 & 11.86 & 0.30 & 2.59 \\
\hline Grecia & 9.45 & 2.60 & 0.00 & 2.92 \\
\hline Holanda & 15.04 & 4.71 & 4.43 & 4.26 \\
\hline Irlanda & 27.62 & 22.01 & 24.82 & 19.87 \\
\hline Italia & 6.45 & 2.75 & 0.00 & 3.50 \\
\hline Luxemburgo & 10.41 & 3.72 & 0.00 & 1.98 \\
\hline Noruega & 85.36 & 44.26 & 44.26 & 44.26 \\
\hline Portugal & 8.14 & 2.63 & 0.00 & 2.81 \\
\hline Reino Unido & 30.10 & 17.59 & 21.59 & 18.30 \\
\hline Suecia & 57.35 & 28.70 & 28.28 & 16.81 \\
\hline
\end{tabular}


de alcohol, vino $11 \%$ de alcohol, productos intermedios $18 \%$ de alcohol.

En base a la aproximación de la escala, podría argumentarse que las políticas del alcohol se han hecho convergentes durante los últimos cincuenta años. Sin embargo, esta convergencia no es sólo consecuencia de que se hayan reducido las diferencias entre los países ECAS. Tal como muestran las figuras 1 y 2, según la escala ECAS, algunos países han cambiado su posición relativa en términos del alcance y del rigor de sus políticas del alcohol. Por ejemplo, Francia y España han ascendido, y Austria y Alemania descendido.

Otro problema de las escalas es que miden las políticas del alcohol únicamente a nivel nacional. En algunos países, como Austria, Bélgica o Alemania, existen importantes variaciones entre las medidas de control del alcohol de unas regiones y otras (cf. e.g., Eisenbach-Stangl y col., 2001; Karlsson \& Österberg, 2001b; Kümmler y col., 2001). Esto se convierte en un verdadero problema, ya que, cuando determinadas medidas de control sólo existen en unas zonas del país, hay que decidir lo que es representativo de todo el estado. Las regulaciones y leyes sobre el alcohol de una región austríaca (land) difícilmente pueden ser representativas de todo el país y viceversa.

Hemos intentado paliar los problemas vinculados a un enfoque basado en las escalas, elaborando unos informes globales sobre las políticas del alcohol de cada país ECAS durante el período 1950-2000, con la ayuda de fuentes escritas e informes orales. (ver Österberg \& Karlsson, 2001b). Al comparar los puntos de la escala en la figura 1 y en la figura 2 con estos informes nacionales, se suele tener la impresión de que en los distintos países ECAS existe un alcance y un rigor relativos en el control del alcohol. Italia, sin embargo, se coloca a un nivel más alto en la figura 2 (así como en la 1) de lo que cabría esperar según su informe nacional. (Allamani, y col., 2001). La explicación más inmediata serían los requisitos necesarios para conseguir una licencia en Italia, las restricciones especiales para la venta de alcohol al público (tanto en locales donde el cliente consume el alcohol en su interior como en locales donde el cliente se lleva la bebida), así como el límite de edad. Todas esas trabas formales son lo bastante importantes para puntuar relativamente alto en la escala ECAS, incluso cuando no han sido verdaderamente respetadas.

Por otra parte, sin embargo, uno no puede evitar sentir que en Italia ha ocurrido -y sigue ocurriendoalgo muy especial en relación con el control del alcohol y los problemas relacionados con el consumo abusivo de dicha sustancia (Allamani y col., 2001). Una especie de control social, semioficial e informal, del alcohol podría en realidad explicar el nivel comparativamente bajo de consumo de alcohol per capita en Italia, comparado con el resto de los países ECAS. Pero lo cierto es que, a pesar de su puntuación relati- vamente elevada en la escala ECAS, Italia no tiene el control estricto y formal del alcohol que poseen los países nórdicos.

A diferencia de Italia, la posición que ocupa Dinamarca en las figuras 1 y 2 es más baja de lo que debería, pues la escala ECAS no incluye los impuestos sobre el consumo de las bebidas alcohólicas. En Dinamarca, dichos impuestos son claramente superiores que en los países de control bajo del alcohol y que en la mayoría de los países de control medio, sea cual sea su definición (ver tabla 1). Uno de los motivos que explican la imagen diferente dada por la puntuación de la escala y el informe del país es que, a comienzos del siglo XX, Dinamarca eligió de forma consciente una política de fuertes tasas impositivas sobre el alcohol como alternativa a las restricciones físicas sobre la accesibilidad del alcohol (Thorsen, Karlsson \& Österberg, 2001).

\section{TENDENCIAS EN LAS DIFERENTES ÁREAS DE LAS POLÍTICAS DEL ALCOHOL}

La figura 3 muestra el rigor de las políticas del alcohol en los países ECAS conforme a las mediciones de la escala ECAS, según los distintos subgrupos de políticas del alcohol, tanto en 1950 como en el 2000. Los dos apartados que obtienen menos puntos en el año 2000 que cincuenta años antes son el control de producción y venta al por mayor y el control de distribución (Figura 3).

En todas las demás áreas de control, las puntuaciones son más altas en el 2000 que en 1950. Por consiguiente, durante los últimos cincuenta años, los cambios experimentados en las áreas de la política del alcohol han sido muy diferentes en los países ECAS. La convergencia que hallamos al observar el desarrollo de las distintas políticas del alcohol parece componerse, al menos, de dos corrientes diferentes. En primer lugar, se ha producido una disminución en el control de la accesibilidad o en el control del aspecto del suministro de la ecuación del alcohol. En segundo lugar, las medidas de control del alcohol parecen en la actualidad ser más estrictas y tener un alcance mayor, y buscan influir en la demanda de bebidas alcohólicas y controlar directamente determinados problemas relacionados con el alcohol.

\section{CONTROL DE PRODUCCIÓNY VENTA AL POR MAYOR}

La tabla 2 muestra cómo el control sobre la producción y la venta al por mayor de bebidas alcohólicas ha descendido, especialmente en la década de 1990, 


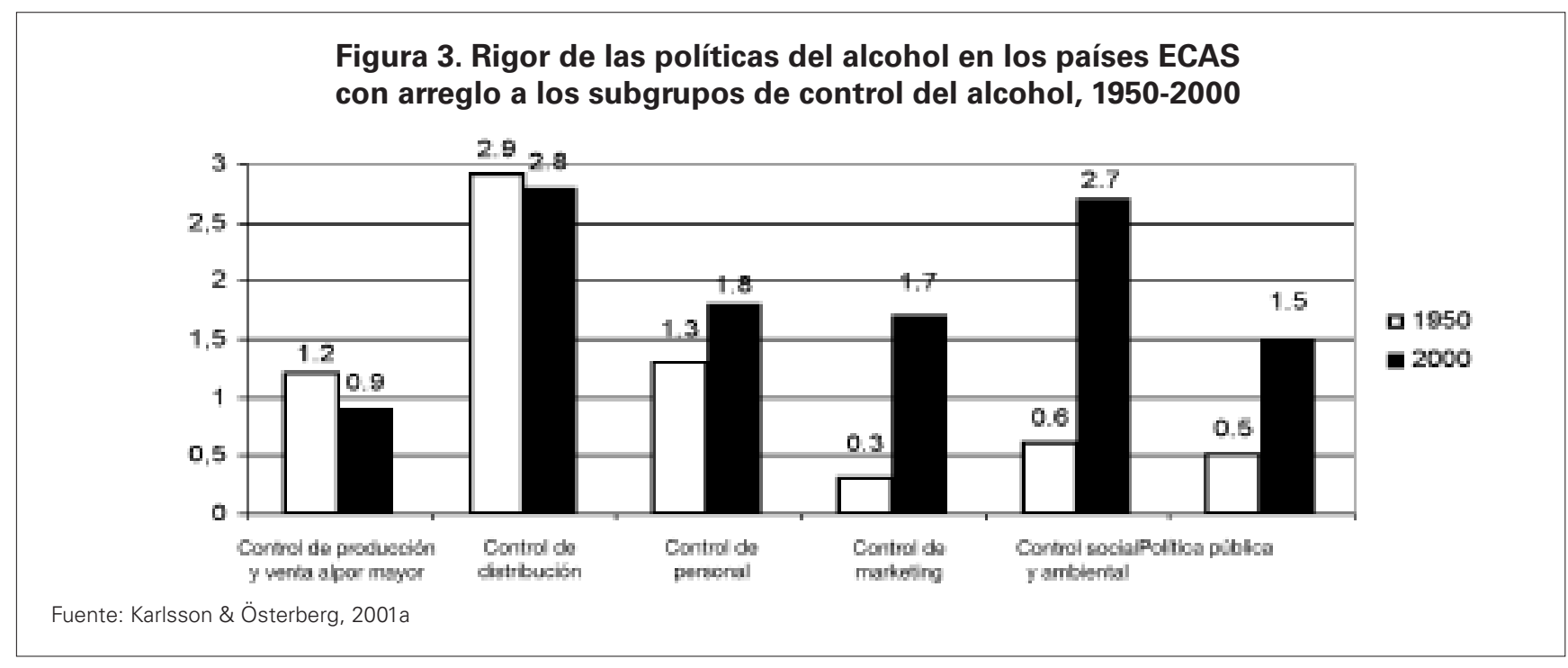

TABLA 2. Rigor de las políticas del alcohol en los países ECAS según los subgrupos de control del alcohol, 1950 -2000

\begin{tabular}{|c|c|c|c|c|c|c|}
\hline Subgrupo & 1950 & 1960 & 1970 & 1980 & 1990 & 2000 \\
\hline $\begin{array}{l}\text { Control de producción y } \\
\text { venta al por mayor ( } 3 \text { p.) }\end{array}$ & 1.2 & 1.3 & 1.3 & 1.3 & 1.3 & 0.9 \\
\hline Control de distribución (7 p.) & 2.9 & 3.0 & 3.0 & 2.8 & 2.9 & 2.8 \\
\hline Control personal (3 p.) & 1.3 & 1.5 & 1.4 & 1.7 & 1.8 & 1.8 \\
\hline Control de marketing (2 p.) & 0.3 & 0.4 & 0.8 & 1.3 & 1.7 & 1.7 \\
\hline Control social y ambiental (3 p.) & 0.6 & 0.9 & 1.2 & 2.0 & 2.3 & 2.7 \\
\hline Política pública (2 p.) & 0.5 & 0.7 & 1.0 & 1.1 & 1.4 & 1.5 \\
\hline
\end{tabular}

Número máximo de puntos para cada subgrupo entre paréntesis.

o para ser más exactos durante los años 1995 y 1996, cuando Finlandia, Noruega y Suecia, a raíz del Acuerdo Económico Europeo (EEA) y de la integración de Finlandia y Suecia en la Unión Europea, se vieron obligadas a abandonar sus sistemas generales de monopolio del alcohol, aboliendo los monopolios estatales sobre la producción, la importación, la exportación y la venta al por mayor (ver Holder y col., 1998; Österberg \& Karlsson, 2001a).

Actualmente, sólo Noruega conserva el monopolio sobre la producción del alcohol, aunque únicamente en el caso de los licores. La tabla 3 nos muestra, asimismo, cómo en casi todos los países ECAS, los productores o vendedores al por mayor de cerveza, vino y licores necesitan una licencia. No obstante, en la mayoría de estos países, la regulación de la producción y venta del alcohol al por mayor no guarda la menor relación con cuestiones de salud pública o política social. Incluso en los países nórdicos, sólo viene determinado por consideraciones legales. En otras palabras, todos los solicitantes que cumplan los requisitos legales, no tener antecedentes legales o impuestos impagados, conseguirán la licencia, ignorando cualquier consideración de carácter preventivo de la política del alcohol. La tarea más importante en dicha regulación es seguir la pista de los actores en el campo del alcohol y asegurar el pago de los impuestos sobre el consumo de alcohol y de los impuestos sobre el valor añadido (Österberg \& Karlsson, 2001a).

\section{CONTROL DE DISTRIBUCIÓN}

Según la escala ECAS, los cambios experimentados en el control de distribución de las bebidas alcohólicas son menores que en el control de producción y venta al por mayor (figura 3). Ello se debe en parte al hecho de que los tres países nórdicos ECAS pudieron mantener el monopolio de los establecimientos de venta de alcohol para consumir en el exterior del local, en la mayoría de las bebidas alcohólicas (tabla 4). En Finlandia, Noruega y Suecia, las compañías estatales de venta de alcohol para consumir fuera del local continúan teniendo el monopolio de todas las bebidas destiladas, vinos enriquecidos y otros productos intermedios, casi todo el vino y todas las cervezas fuertes. Al igual que ocurre con la producción y la venta al por mayor, en la mayoría de los países ECAS, la concesión de licencias para la venta de alcohol, tanto en establecimientos donde se consume dentro del local como en establecimientos donde se consume fuera del 
TABLA 3. Control de producción y venta al por mayor de bebidas alcohólicas en los países de la ECAS en el año 2000

\begin{tabular}{|c|c|c|c|}
\hline País & Monopolio Estatal & Licencia & No licencia \\
\hline Alemania & & & $C, V, L$ \\
\hline Austria & & & $C, V, L$ \\
\hline Bélgica & & $C, V, L$ & \\
\hline Dinamarca & & & $C, V, L$ \\
\hline España & & $C, V, L$ & \\
\hline Finlandia & & $C, V, L$ & \\
\hline Francia & & $C, V, L$ & \\
\hline Grecia & & $C, V, L$ & \\
\hline Holanda & & $C, V, L$ & \\
\hline Irlanda & & $C, V, L$ & \\
\hline Italia & & $C, V, L$ & \\
\hline Luxemburgo & & & $C, V, L$ \\
\hline Noruega & & $C, V, L$ & \\
\hline Portugal & & $C, V, L$ & \\
\hline Reino Unido & & $C, V, L$ & \\
\hline Suecia & & $C, V, L$ & \\
\hline
\end{tabular}

(C=cerveza, V=vino, L=licores)

Tabla 4. Control de venta de bebidas alcohólicas para consumir fuera del local en los países ECAS en el año 2000

\begin{tabular}{|c|c|c|c|}
\hline País & Monopolio Estatal & Licencia & No licencia \\
\hline Alemania & & & $C, V, L$ \\
\hline Austria & & & $C, V, L$ \\
\hline Bélgica & & $C, V, L$ & \\
\hline Dinamarca & & & $C, V, L$ \\
\hline España & & & $C, V, L$ \\
\hline Finlandia & $V_{1} L$ & C & \\
\hline Francia & & $C, V, L$ & \\
\hline Grecia & & $C, V, L$ & \\
\hline Holanda & & $C, V, L$ & \\
\hline Irlanda & & $C, V, L$ & \\
\hline Italia & & $C, V, L$ & \\
\hline Luxemburgo & & $C, V, L$ & \\
\hline Noruega & $V_{1} L$ & B & \\
\hline Portugal & & & $C, V, L$ \\
\hline Reino Unido & & $C, V, L$ & \\
\hline Suecia & $V_{1} L$ & C & \\
\hline
\end{tabular}

( $C=$ cerveza, $V=$ vino, $L=$ licores)

local, es en nuestros días un asunto puramente legal: el solicitante no debe tener antecedentes penales o impuestos impagados. En algunos países, sin embargo, los solicitantes han de tener cierta formación para conseguir una licencia que les permita vender bebidas alcohólicas en sus establecimientos. Un ejemplo de ello sería Holanda (Karlsson \& Österberg, 2001e).

En los países ECAS, los acuerdos de los monopolios estatales no incluyen los establecimientos de venta de bebidas alcohólicas para consumir dentro del local (tabla 5). Durante los últimos cincuenta años, el monopolio estatal finlandés sobre el alcohol es el único que ha tenido sus propios restaurantes, si bien la mayoría de éstos eran privados. Hasta mediados de la década de 1990, sin embargo, las cuestiones relacionadas con la política preventiva del alcohol eran cruciales, o al menos importantes, a la hora de conceder licencias a restaurantes en los países nórdicos con monopolio (cf. e.g., Österberg, 1989, 126-128; Holder y col., 1998).

Además de la concesión de licencias, los gobiernos cuentan con muchos otros medios para controlar la venta al público de bebidas alcohólicas. El control de distribución incluye numerosas restricciones en los establecimientos que venden alcohol para consumir tanto dentro como fuera del local, como, por ejemplo, 
TABLA 5. Control de venta de bebidas alcohólicas para consumir dentro del local en los países ECAS en el año 2000

\begin{tabular}{|c|c|c|c|}
\hline País & Monopolio Estatal & Licencia & No licencia \\
\hline Alemania & & & $C, V, L$ \\
\hline Austria & & & $C, V, L$ \\
\hline Bélgica & & $C, V, L$ & \\
\hline Dinamarca & & $C, V, L$ & \\
\hline España & & & $C, V, L$ \\
\hline Finlandia & & $C, V, L$ & \\
\hline Francia & & & $C, V, L$ \\
\hline Grecia & & $C, V, L$ & \\
\hline Holanda & & $C, V, L$ & \\
\hline Irlanda & & $C, V, L$ & \\
\hline Italia & & $C, V, L$ & \\
\hline Luxemburgo & & $C, V, L$ & \\
\hline Noruega & & $C, V, L$ & \\
\hline \multicolumn{4}{|l|}{ Portugal } \\
\hline Reino Unido & & $C, V, L$ & \\
\hline Suecia & & $C, V, L$ & $C, V, L$ \\
\hline
\end{tabular}

$(\mathrm{C}=$ cerveza, $\mathrm{V}=$ vino, $\mathrm{L}=$ licores $)$

límites especiales en los días, horas o lugares que pueden vender alcohol; regulación de los tipos de comercios, restaurantes o ambientes donde no se permite la venta de este producto; límite máximo en el número de comercios o restaurantes donde se puede vender en todo el país o en algunas regiones determinadas; reglas que definen la cantidad de alcohol que puede comprar un cliente; normas que establecen en qué clase de envases puede venderse. A menudo este tipo de regulaciones son, o han sido, muy detalladas, y lo cierto es que no sólo existen en los países nórdicos.

En Irlanda, por ejemplo, no se venden bebidas alcohólicas en los pubs ni el día de Navidad ni el Viernes Santo. Los lunes, martes y miércoles, los establecimientos con licencia para vender alcohol abren de 10.30 a.m a 11.30 p.m, y treinta minutos más a lo largo de todo el año. En cuanto a los jueves, viernes y sábados, el horario de apertura es a las 12.30 a.m., más treinta minutos extra a lo largo de todo el año. Los domingos, el horario es de 12.30 a.m a 11 p.m. En Italia está prohibida la venta de bebidas con más del $21 \%$ de alcohol entre las 10 a.m y las 6 a.m en establecimientos situados junto a las autopistas. En España, no pueden venderse bebidas alcohólicas a menores de 18 años entre las 12 de la noche y las 6 de la madrugada. El consumo de bebidas alcohólicas en España está, asimismo, prohibido en estadios deportivos. Y en Bélgica está prohibido servir licores en hospitales, colegios y demás lugares a los que los menores tengan acceso. En Francia, como en muchos otros países ECAS, las máquinas expendedoras tienen prohibida la venta de alcohol. En Inglaterra y Gales, no se permite la venta de bebidas alcohólicas en las gasolineras. En la década de 1950, la cantidad mínima de alcohol que se podía comprar en Bélgica para consumir fuera del local eran dos litros de licor; mientras que en Finlandia, en la misma época, sólo se podía comprar un máximo de dos litros. En Holanda, la política del alcohol en la década de 1950 estaba basada en las restricciones sobre el número de puntos de venta por habitante. En Holanda, en nuestros días, los establecimientos con autorización para vender alcohol -para consumir fuera del local- no deben estar directamente conectados con los que suministran alimentos. Eso significa que los establecimientos con licencia para vender bebidas alcohólicas han de tener una entrada y un personal independiente. Las bebidas alcohólicas tampoco pueden ser vendidas en quioscos; es decir, a través de una ventanilla. Hace muchos años que también resulta inadmisible tener un punto de venta de alcohol para consumir tanto fuera como dentro del local en un mismo establecimiento, y el Ministerio de Sanidad tiene autoridad para desautorizar la venta de alcohol en los estadios de fútbol, colegios, piscinas, hospitales, etc... desde el año 2000. En Alemania, puede prohibirse la venta completa o parcial de bebidas alcohólicas en algunos períodos o lugares, si resulta necesario para mantener el orden público. Esta normativa se aplica, por ejemplo, en partidos de fútbol o conciertos. En Dinamarca, la cerveza no puede venderse en latas (Österberg \& Karlsson, 2001a).

Las restricciones gubernamentales en la venta al público varían enormemente de unos países ECAS a otros, aunque, en términos generales, podría decirse que han perdido más que ganado terreno durante las últimas cinco décadas (para más detalles ver Österberg \& Karlsson, 2001a). En muchos países, el número de días y horas de venta al público de alcohol para 
consumir fuera del local es mayor que a principios de la década de 1950. Ello afecta especialmente a los países nórdicos. También es difícil en nuestros días encontrar normas que regulen las cantidades de alcohol que se pueden comprar en los países ECAS. Asimismo, la regulación sobre la bebida en los restaurantes, que solía ser muy parecida en los países nórdicos, así como la regulación de las horas de apertura y de las ventas para consumir dentro del local en Irlanda y el Reino Unido se han ido relajando a lo largo de los años. Sin embargo, también algunos países han restringido la accesibilidad del alcohol en los últimos cincuenta años, prohibiendo su venta en las gasolineras o en las cantinas de los lugares de trabajo, como ocurre en Italia y Francia. En Holanda, se prohibió vender bebidas alcohólicas en gasolineras y tiendas de no comestibles en otoño del año 2000. También el vandalismo de los seguidores del fútbol ha contribuido a la entrada en vigor de algunas restricciones en la venta de alcohol en los estadios de fútbol y sus alrededores.

En este contexto es importante, asimismo, resaltar que en algunos países no existen esa clase de limitaciones especiales en la venta de alcohol al público, pero las normas generales sobre la venta para el consumo dentro y fuera del establecimiento también regulan la accesibilidad de las bebidas alcohólicas. De hecho, en algunos países la hora de cierre de los restaurantes puede ser en la práctica más estricta, sin que exista ninguna medida de control del alcohol, que en otros países donde una reglamentación estatal controle el consumo de alcohol en los restaurantes. Esto resulta difícil de demostrar, ya que en los países sin restricciones sobre las horas de venta de bebidas alcohólicas, existen sin la menor duda algunos lugares donde el alcohol puede comprarse para consumir fuera prácticamente a cualquier hora. Pero para un viajero, por ejemplo, sin especial conocimiento de las costumbres y de las condiciones locales, puede resultar bastante difícil conseguir bebidas alcohólicas para consumir fuera del establecimiento a las 8 p.m, o en el interior de éste hacia la medianoche, en algunos países sin restricciones legales, si lo comparamos, por ejemplo, con Finlandia, donde muchos comercios con monopolio permanecen abiertos entre semana hasta las 8 p.m y numerosos restaurantes sirven bebidas alcohólicas hasta las 4 a.m.

\section{CONTROL PERSONAL}

Durante los últimos cincuenta años, varios países ECAS que no tenían límites de edad en la década de 1950 han empezado a delimitar la edad legal para comprar bebidas alcohólicas; entretanto, otros países han aumentado dichos límites. Durante esos años, por ejemplo, Dinamarca ha abandonado la política de no poner límite a la edad en la venta de alcohol para consumir fuera del local, y en 1998 puso la edad límite en los 15 años. Los límites legales de edad fueron también gradualmente introducidos en Francia entre 1954 y 1959. Los países con edades límite más estrictas en el 2000 que en 1950 son Dinamarca, Francia, Alemania, Portugal y España. El cambio total en este aspecto es todavía mayor de lo que muestra la media de la escala ECAS, ya que Finlandia y Suecia han bajado sus límites de edad durante el período estudiado (Österberg \& Karlsson, 2001a).

La tabla 6 resume la situación con respecto a los límites de edad en la venta de bebidas alcohólicas para consumir dentro y fuera de un establecimiento en el año 2000. Por el momento, Bélgica, Grecia y Portugal parecen ser los únicos países ECAS que no tienen límites de edad, al menos para algunas bebidas alcohólicas y su venta para consumir fuera del local. Todos los países ECAS tienen una edad límite para la venta de licores para consumir dentro del local. En los países ECAS, el límite de edad oscila entre los 15 y los 20 años. Por regla general, los límites de edad son más elevados para licores que para cerveza y vino. Normalmente, son iguales en la venta para consumir en el exterior y en el interior del establecimiento. En Dinamarca, el límite de edad es más bajo en el primero de los casos (consumir fuera del local) que en el segundo (consumir dentro del local), mientras que en Finlandia, Suecia y el Reino Unido encontramos que el límite de edad es más bajo en el segundo que en el primero de los casos.

En realidad, los cambios en el área del control personal han sido incluso más drásticos de lo que muestra la escala. Por ejemplo, Suecia abolió el sistema de racionamiento Bratt en 1955, y Finlandia ha abandonado gradualmente un sistema similar de control personal entre los últimos años de la década de 1940 y el año 1971 (Karlsson \& Österberg, 2001c; 2001i). Eso significa que en relación con el control personal han existido dos tendencias divergentes en los países ECAS. Los países nórdicos con monopolio han relajado sus medidas de control, mientras que el límite de edad se ha vuelto más estricto en muchos otros países ECAS.

En muchos países ECAS existen normas oficiales que impiden vender bebidas alcohólicas a personas en estado de embriaguez. En otros países ECAS ésta puede constituir una regla no escrita. 
TABLA 6. Límites de edad en la venta de bebidas alcohólicas para consumir dentro y fuera del local en los países ECAS en el año 2000

\begin{tabular}{|c|c|c|c|c|c|c|}
\hline \multirow[t]{2}{*}{ País } & \multicolumn{3}{|c|}{ Fuera del local } & \multicolumn{3}{|c|}{ Dentro del local } \\
\hline & Cerveza & Vino & Licores & Cerveza & Vino & Licores \\
\hline Alemania & 16 & 16 & 18 & 16 & 16 & 18 \\
\hline Austria' & 16 & 16 & 18 & 16 & 16 & 18 \\
\hline Bélgica² & - & - & 18 & 16 & 16 & 18 \\
\hline Dinamarca & 15 & 15 & 15 & 18 & 18 & 18 \\
\hline España ${ }^{3}$ & 16 & 16 & 16 & 16 & 16 & 16 \\
\hline Finlandia & 18 & 18 & 20 & 18 & 18 & 18 \\
\hline Francia ${ }^{4}$ & 16 & 16 & 16 & 16 & 16 & 16 \\
\hline Grecia & - & - & 18 & - & - & 18 \\
\hline Holanda & 16 & 16 & 18 & 16 & 16 & 18 \\
\hline Irlanda & 18 & 18 & 18 & 18 & 18 & 18 \\
\hline Italia & 16 & 16 & 16 & 16 & 16 & 16 \\
\hline Luxemburgo & - & - & - & 18 & 18 & 18 \\
\hline Noruega & 18 & 18 & 20 & 18 & 18 & 20 \\
\hline Portugal & - & - & - & 16 & 16 & 16 \\
\hline Reino Unido ${ }^{5}$ & 18 & 18 & 18 & 16 & 16 & 18 \\
\hline Suecia & 18 & 20 & 20 & 18 & 18 & 18 \\
\hline
\end{tabular}

1 Las regulaciones sobre el límite de edad legal difieren considerablemente de un lugar a otro del país (entre los 15 y los 18 años, según la región).

2 Cualquier menor de 16 años, excepto si está casado o acompañado de uno de sus padres o tutor, tiene prohibido entrar en una sala de baile donde se sirvan bebidas fermentadas o en cualquier establecimiento con licencia para vender alcohol donde se baile.

3 No existe límite de edad para el consumo de cerveza y vino dentro o fuera del local si el joven está acompañado de uno de sus padres o tutor. En algunas regiones, el límite de edad legal para consumir licor es de 18 años.

4 No existe límite de edad para el consumo de alcohol dentro del local si el joven está acompañado de uno de sus padres o tutor.

5 Las personas de 16 o más años de edad pueden comprar cerveza rubia o negra, sidra de manzana o de pera (en Escocia también vino) si consumen una comida (excepto en la barra).

\section{CONTROL DE MARKETING DE LAS BEBIDAS ALCOHÓLICAS}

El control de marketing de las bebidas alcohólicas ha ido aumentando desde el principio hasta el fin del período estudiado, especialmente a partir de la década de 1960. La tabla 7 resume la situación en el año 2000.

En los primeros años de la década de 1950, la publicidad del alcohol apenas estaba regulada en toda Europa. En las décadas de 1960 y de 1970, la publicidad de las bebidas alcohólicas -sobre todo en radio y televisión- se vio más controlada, y en varios países empezaron a surgir una serie de limitaciones de carácter general, fundamentalmente en forma de códigos voluntarios aunque también como legislación. Ello estaba sin duda relacionado con el hecho de que el número de televisores y de programas de televisión había crecido de forma sustancial durante este período (Karlsson \& Simpura, 2001).

Tal como puede verse en la tabla 7, las regulaciones nacionales sobre el marketing de las bebidas alcohólicas difieren sustancialmente según el país en cuestión. Por ejemplo, en Grecia no existen actualmente restricciones para la publicidad, la promoción de ventas y la esponsorización de las bebidas alcohólicas (Gefou-Madianou, Karlsson \& Österberg, 2001). En Noruega, en cambio, la situación es diametralmente opuesta, pues tanto la propaganda como la espon- sorización del alcohol están prácticamente prohibidas (Karlsson \& Österberg, 2001f). En la mayoría de los países ECAS, la publicidad del alcohol está en nuestros días regulada por códigos voluntarios. En los países nórdicos, sin embargo, dicha propaganda lleva mucho tiempo regulada por un control legal. Resulta interesante el desarrollo experimentado por Finlandia, donde en 1976 se prohibió cualquier forma de publicidad de bebidas alcohólicas, hasta que en 1995 se volvió a permitir la propaganda de cerveza, vino y bebidas intermedias (see Alavaikko \& Österberg, 2000). La actitud hacia la publicidad del alcohol, especialmente en los estadios deportivos, se ha vuelto más negativa en los países ECAS. Durante la última década, varios países del sur de Europa, como Francia y España, y en el 2001 también Portugal, han desautorizado la propaganda del alcohol en los estadios deportivos.

A nivel de la Unión Europea, la publicidad del alcohol está regulada por el Consejo Directivo 89/552/EEC para la coordinación de ciertas disposiciones establecidas por la ley, y la regulación o acción administrativa en los estados miembro de todo lo relacionado con la búsqueda de actividades televisivas (también llamado "Televisión sin fronteras"). La directiva, aprobada originalmente en octubre de 1989, fue enmendada en parte en junio de 1997 mediante la directiva 97/36/EC del Parlamento y del Consejo Europeo. La directiva modificada establece un marco legal muy firme que permite a los operadores televisivos desarrollar sus 
TABLA 7. Forma primaria de las regulaciones para el marketing de las bebidas alcohólicas en los países ECAS durante el año 2000

\begin{tabular}{|c|c|c|c|}
\hline País & Control Legal & Control Voluntario & No regulación \\
\hline Alemania $^{1}$ & & $X$ & \\
\hline Austria $^{2}$ & & $X$ & \\
\hline Bélgica $^{3}$ & & $X$ & \\
\hline Dinamarca $^{4}$ & & $X$ & \\
\hline España $^{5}$ & $x$ & & \\
\hline Finlandia ${ }^{6}$ & $X$ & & \\
\hline Francia $^{7}$ & $x$ & & \\
\hline Grecia $^{8}$ & & & $X$ \\
\hline Holanda ${ }^{9}$ & & $X$ & \\
\hline Irlanda ${ }^{10}$ & & $X$ & \\
\hline Italia"11 & & $X$ & \\
\hline Luxemburgo $^{12}$ & & $X$ & \\
\hline Noruega $^{13}$ & $X$ & & \\
\hline Portugal ${ }^{14}$ & & & $X$ \\
\hline Reino Unido ${ }^{15}$ & & $x$ & \\
\hline Suecia ${ }^{16}$ & $X$ & & \\
\hline
\end{tabular}

1 En Alemania, la publicidad de las bebidas alcohólicas está regulada por un código voluntario. Existen algunas normas especiales sobre la propaganda del alcohol en los estadios deportivos.

2 En Austria, la publicidad de las bebidas alcohólicas está regulada por unas pautas de carácter voluntario. En algunos lugares está prohibida. La televisión estatal y las emisoras de radio están parcialmente reguladas por controles legales.

3 En Bélgica, la publicidad de las bebidas alcohólicas está básicamente regulada por un control voluntario. En algunos marcos, por ejemplo hospitales y ambientes de trabajo, dicha propaganda está prohibida.

4 En Dinamarca, la publicidad de las bebidas alcohólicas está regulada por un código voluntario. No se permite dicha propaganda en la televisión estatal y en las emisoras de radio.

5 En España, la publicidad de las bebidas alcohólicas está regulada principalmente por un control legal. No está reglamentada la publicidad de la cerveza en quioscos y otros establecimientos de venta.

Está prohibido anunciar licores en la televisión estatal y en las emisoras de radio, así como patrocinar bebidas alcohólicas en relación con los deportes.

6 En Finlandia, se permite la publicidad de las bebidas alcohólicas que tengan hasta un $22 \%$ de alcohol.

7 En Francia, está autorizada la publicidad de bebidas alcohólicas, aunque existe un fuerte control. Por ejemplo, la propaganda del alcohol no se permite en los estadios deportivos

8 En Grecia, la publicidad de las bebidas alcohólicas apenas está regulada. La propaganda de licores está prohibida en tiendas de deportes y en programas de televisión. Este control, sin embargo, es casi inexistente.

9 En Holanda, la publicidad de las bebidas alcohólicas está regulada por un sistema de control voluntario.

10 En Irlanda, no hay un control separado de la publicidad de bebidas alcohólicas. Existe, sin embargo, un código voluntario vigente en la televisión estatal y en las emisoras de radio, así como en las salas de cine.

11 En Italia, la publicidad de las bebidas alcohólicas está regulada en parte por un control legal y en parte por unas pautas voluntarias.

12 En Luxemburgo, la publicidad de las bebidas alcohólicas está regulada por un sistema de control voluntario que, sin embargo, no parece ser demasiado respetado.

13 Noruega posee la regulación más estricta de toda Europa para la publicidad de las bebidas alcohólicas. La propaganda del alcohol está en la práctica completamente prohibida.

14 En Portugal, la publicidad de las bebidas alcohólicas está sólo regulada en la televisión estatal y en las emisoras de radio. Aparte de éste, no existe ningún otro control.

15 En el Reino Unido, la publicidad de las bebidas alcohólicas está regulada en parte por un control legal y en parte por unas pautas voluntarias.

16 En Suecia, la publicidad de las bebidas alcohólicas está regulada por un control legal. La propaganda en emisiones de televisión y radio está prohibida. Ello no incluye, sin embargo, las bebidas con menos de $2.25 \%$ de alcohol.

actividades en la Unión Europea. El objetivo principal era crear las condiciones necesarias para el movimiento libre de las emisiones televisivas.

La directiva también incluye algunas restricciones sobre la publicidad del alcohol en radio y televisión. El artículo de la directiva establece que la publicidad de las bebidas alcohólicas tiene que obedecer los siguientes criterios:

- No debe ser destinada a los menores o, en particular, presentar a menores consumiendo esa clase de bebidas.

- No debe vincular el consumo de alcohol a una mejora del rendimiento físico o a la conducción de un vehículo.

- No debe crear la impresión de que el consumo de alcohol contribuye al éxito social o sexual.

- No debe reivindicar que el alcohol tenga cualidades terapéuticas, sea un estimulante, un sedativo o un medio de resolver conflictos personales.
- No debe alentar el consumo desmedido de alcohol ni presentar la abstinencia o la moderación en la bebida como algo negativo.

- No debe poner énfasis en que un alto contenido de alcohol sea una cualidad positiva de las bebidas.

\section{CONTROL DE LA CONDUCCIÓN DE VEHÍCULOS EN ESTADO DE EMBRIAGUEZ}

La conducción de vehículos en estado de embriaguez es un área en la que el control de los problemas relacionados con el alcohol se ha endurecido. Se produjeron grandes cambios sobre todo en la década de 1970 (tabla 19.2). En una fecha tan tardía como 1970, había seis países ECAS que no habían establecido un límite legal de concentración de alcohol en sangre (BAC) para conducir. En el año 2000, todos los países ECAS tenían un límite legal, que en ningún caso supe- 
raba el 0,08\%. La tabla 8 resume la situación en el año 2000.

Un factor que ha contribuido al desarrollo de los límites BAC ha sido el incremento del número de vehículos de motor que circulan por las carreteras. Especialmente en la década de 1970, el tráfico creció hasta tal punto que se hizo necesaria una regulación más estrecha del tema, así como prestar más atención a los problemas de seguridad vial, como por ejemplo la conducción en estado de embriaguez (Karlsson \& Österberg, 2001a). El número cada vez mayor de vehículos de motor y la toma de conciencia por parte de los ciudadanos de los problemas de seguridad en la carretera contribuyeron sin duda a la introducción de los límites BAC en la mayoría de los países ECAS en las décadas de 1970 y de 1980. Es evidente que también los avances tecnológicos, sobre todo en el caso de los alcoholímetros, cada vez más económicos y precisos, han influido en este proceso. Con todo, el hecho de que no existieran límites BAC en la década de 1950 no quiere decir necesariamente que el control de la conducción de vehículos en estado de embriaguez fuera inexistente. Por ejemplo, en Finlandia se ha considerado un delito conducir ebrio desde 1926. En 1950, el período máximo de encarcelamiento fue aumentado a cuatro años y en 1959 el test de alcoholemia y los exámenes clínicos se convirtieron en obligatorios, si bien hasta 1977 no fueron introducidos los límites BAC de forma legal (Österberg, 1987).

En la actualidad, los límites legales BAC más estrictos entre los países ECAS se encuentran en los países nórdicos. Suecia y Noruega, aunque también Portugal, tienen un límite BAC del $0.02 \%$. El límite legal BAC más elevado, el 0.08\%, se halla en Irlanda, el Reino Unido y Luxemburgo. El resto de los países ECAS tienen unos límites legales BAC del 0.05\%. Algunos países ECAS también establecen diferentes límites legales BAC para los conductores principiantes o los profesionales. Por ejemplo, en España se aplica un límite BAC del $0.03 \%$ a los conductores principiantes y a los profesionales (Karlsson \& Österberg, 2001h).

\section{PREVENCIÓN NACIONAL DEL ALCOHOL Y PROGRAMAS EDUCATIVOS}

A principios de la década de 1950, muy pocos países ECAS tenían un plan nacional de prevención del alcohol, o programas educativos, u organismos que se encargaran de esa clase de actividades. Actualmente, la mayoría de los países ECAS cuentan con un programa especial y con organismos dedicados a la prevención o a la educación en el campo del alcohol. (Figura 3; Tabla 8). Una explicación de este fenómeno sería que, en nuestros días, los países ECAS tienen, por lo general, muchos más programas preventivos y educativos que hace cincuenta años.

Los programas preventivos o educativos no se limitan a adoptar medidas de control. El motivo más importante para documentar su existencia es que son un indicativo del lugar que ocupa el control del alcohol en la sociedad. La existencia de un programa preventivo o educativo en el campo del alcohol sirve para mostrar qué política preventiva del alcohol se ha adoptado en uno u otro sentido de la agenda política, y

TABLA 8. Límites de concentración de alcohol en sangre (BAC) para conducir en los países ECAS en el año 2000, en tanto por ciento

\begin{tabular}{|lc|}
\hline País & Límite BAC (\%) \\
\hline Alemania & 0.05 \\
\hline Austria & 0.05 \\
\hline Bélgica & 0.05 \\
\hline Dinamarca & 0.05 \\
\hline España & 0.05 \\
\hline Finlandia & 0.05 \\
\hline Francia & 0.05 \\
Grecia & 0.05 \\
\hline Holanda & 0.05 \\
\hline Irlanda & 0.08 \\
\hline Italia1 & 0.08 \\
\hline Luxemburgo & 0.08 \\
Noruega2 & 0.05 \\
\hline Portugal3 & 0.05 \\
Reino Unido & 0.08 \\
\hline Suecia & 0.02 \\
\hline
\end{tabular}

1 El límite BAC en Italia descendió a 0.05 en el otoño de 2001.

2 El límite BAC en Noruega descendió a 0.02 en enero de 2001.

3 El límite BAC en Portugal descendió a 0.02 en mayo de 2001. 
TABLA 9. Existencia de programas nacionales para la prevención y la educación en el campo del alcohol en los países de la ECAS en el año 2000

\begin{tabular}{|c|c|c|}
\hline País & Programa Nacional de Prevención del Alcohol & Programa Nacional de Educación sobre el Alcohol \\
\hline \multicolumn{3}{|l|}{ Alemania } \\
\hline \multicolumn{3}{|l|}{ Austria } \\
\hline Bélgica & $X$ & $X$ \\
\hline \multicolumn{3}{|l|}{ Dinamarca } \\
\hline España & $X$ & $X$ \\
\hline Finlandia & $X$ & $X$ \\
\hline Francia & $X$ & $X$ \\
\hline \multicolumn{3}{|l|}{ Grecia } \\
\hline Holanda & $X$ & $X$ \\
\hline Irlanda & $X$ & $X$ \\
\hline Italia & $X$ & $X$ \\
\hline \multicolumn{3}{|l|}{ Luxembur-go } \\
\hline Noruega & $x$ & $x$ \\
\hline Portugal & $X$ & $X$ \\
\hline Reino Unido & $X$ & $x$ \\
\hline Suecia & $x$ & $x$ \\
\hline
\end{tabular}

que, al menos, algunos problemas sociales o de salud pública se han catalogado como problemas relacionados con el alcohol. En algunos casos, esos programas son más un reflejo de la cooperación internacional que una imperiosa necesidad nacional de controlar los problemas relacionados con el alcohol. Sin embargo, a pesar de los mecanismos que han servido para desarrollar esos programas, su sola existencia sirve para que la administración del estado y la estructura política se vean obligados a crear organismos que lleven adelante esos planes y a informar sobre el cumplimiento de sus objetivos tanto a nivel nacional como internacional.

\section{IMPUESTOS SOBRE EL CONSUMO DE ALCOHOL}

La armonización de los impuestos indirectos dentro de la Unión Europea ha sido un elemento importante en la estrategia global de crear un mercado europeo único. La esencia de la propuesta de 1972 fue que la armonización de los impuestos sobre el consumo tuviera lugar en dos fases. En primer lugar, debían armonizarse las estructuras del impuesto y, posteriormente, coordinarse sus tasas. Sin entrar en detalles sobre el dicho proceso, el resultado fue que en 1992, según la directiva 92/83/EEC, todos los estados miembro tenían que aplicar una tasa mínima de 550 euros por hectolitro de alcohol puro sobre el producto final. Además de la tasa mínima, se fijaba también una tasa objetivo de 1,000 euros para los licores. Los países cuyas tasas estaban por debajo de ésta no podían reducir sus impuestos sobre los licores, y los países cuyas tasas estaban por encima no podían bajar de la tasa objetivo. La tasa mínima sobre los pro- ductos intermedios se fijaba en 45 euros por hectolitro. Para los productos intermedios que no excedían el $15 \%$ de alcohol, la tasa podía ser más baja, pero no inferior al $40 \%$ por debajo de la tasa estándar nacional ni menor que la tasa actual para vinos no gaseosos. La tasa mínima para el vino, así como para las bebidas fermentadas que no eran ni vino ni cerveza, se fijaba en cero. La tasa mínima para la cerveza se fijaba en 1.87 euros por hectolitro y grado de alcohol en el producto final o en 0.748 euros por hectolitro y grado de Plato en el producto final (Österberg \& Karlsson, 2001c).

A pesar de que existen algunas excepciones a la regla general de los impuestos sobre el consumo de las bebidas alcohólicas dentro de la Unión Europea, la armonización de la estructura de dichos impuestos nos ayuda a comparar el nivel actual de impuestos sobre el consumo en los países ECAS. Por otra parte, nuestros datos sobre los impuestos especiales del alcohol no abarcan todo el período 1950-2000. En los informes de cada país, es posible seguir generalmente los cambios en los impuestos especiales sobre el alcohol desde principios de la década de 1970 hasta el año 2000, y el empleo del índice del coste de la vida da una amplia descripción de los cambios en los niveles reales de los impuestos sobre el consumo para las diferentes categorías de bebidas en los países ECAS (ver Österberg \& Karlsson, 2001a). Debido a que los métodos para recaudar impuestos sobre el alcohol eran muy diferentes, y en algunos países ECAS también muy complicados, y debido a los diferentes valores en los cambios de divisa, resultó, sin embargo, imposible documentar con precisión en forma de tabla las décadas anteriores. 
En la tabla 1, los impuestos sobre el consumo de diferentes bebidas alcohólicas se han calculado en base a un litro de alcohol puro en el producto final. La tabla muestra la existencia de una gran variedad entre los porcentajes impositivos sobre el alcohol en los diferentes países ECAS. En un extremo tenemos a los países mediterráneos, Grecia, Italia, Portugal y España, con tasas impositivas muy bajas en cada categoría de bebidas. En el otro extremo tenemos a los países nórdicos, Finlandia, Noruega y Suecia, con tasas muy altas sobre el alcohol en cada categoría. Dinamarca, Irlanda y el Reino Unido también tienen tasas altas sobre el alcohol. Austria, Bélgica, Francia, Alemania y Holanda están en un punto medio. Sin embargo, si estos países son productores de vino, normalmente fijan la tasa impositiva sobre el vino en 0 euros.

En todos los países ECAS, las tasas impositivas sobre el alcohol calculadas en base al contenido de alcohol puro son mayores para los licores que para cualquier otra bebida alcohólica. En Irlanda, Suecia y el Reino Unido, la tasa impositiva más baja sobre el alcohol es para la cerveza. En Bélgica, Holanda y Noruega, las tasas impositivas son aproximadamente las mismas para productos intermedios, vino y cerveza. Finalmente, en la mayoría de los países ECAS, el vino tiene la tasa impositiva más baja. De hecho, en seis países ECAS la tasa sobre el vino es 0 . Por otra parte, en Portugal, el impuesto sobre el valor añadido es más bajo para el vino que para otras bebidas alcohólicas.

\section{DIFERENCIAS, SIMILITUDES Y TENDENCIAS EN LAS POLÍTICAS DEL ALCOHOL DE LOS PAÍSES ECAS}

A principios de la década de 1950, existían importantes diferencias entre las políticas del alcohol de los países ECAS. En todos los países nórdicos ECAS, las políticas del alcohol se basaban en elevados impuestos sobre el consumo de bebidas alcohólicas y, a excepción de Dinamarca, en unos sistemas de monopolio estatal y en unos controles muy estrictos sobre los ciudadanos. En los países mediterráneos ECAS, había muy pocas medidas vigentes, y algunas de ellas tenían su origen en intereses industriales o comerciales. Podría argumentarse que en el Mediterráneo y en muchos países centroeuropeos no se conocía siquiera el término "política del alcohol."

Si lo comparamos con los países nórdicos ECAS, los impuestos especiales sobre las bebidas alcohólicas, especialmente sobre el vino, eran muy bajos en los países mediterráneos ECAS a principios de la década de 1950. Como el vino era la bebida claramente predilecta de esos países, los consumidores de los países mediterráneos apenas pagaban impuestos sobre el alcohol en comparación con los bebedores nórdicos, que, aunque consumían mucha menos cantidad, se concentraban en el consumo de licores, las bebidas con tasas impositivas más altas en esos países.

En los países centroeuropeos ECAS donde la cerveza era la bebida preferente, la gente también consumía licores, o al menos lo había hecho antes. Muchos de esos países tenían, además, un pasado de campañas antialcohólicas. A principios de la década de 1950, algunos de estos países, por ejemplo Irlanda y el Reino Unido, tenían un sistema muy riguroso y eficaz de licencias, especialmente para la venta al público de bebidas alcohólicas para consumir en el interior del establecimiento. Otros, como por ejemplo Bélgica y Holanda, conservaban vigentes algunos vestigios de un sistema anterior de control del alcohol mucho más estricto. Normalmente, los países centroeuropeos consumidores de cerveza también recaudaban impuestos especiales sobre las bebidas alcohólicas. Debemos, sin embargo, admitir que el término "países centroeuropeos consumidores de cerveza" no es demasiado correcto, pues existen diferencias sistemáticas en la dimensión este-oeste de las políticas del alcohol en esos países.

La segunda mitad del siglo XX parece un período de convergencia en las políticas del alcohol de los países ECAS. Sin embargo, sería difícil explicar la tendencia convergente haciendo referencia a las modas similares de los grupos de países en base a su bebida predilecta o a su situación geográfica. La tendencia convergente puede entenderse mejor al contemplar las modas en las diferentes áreas de la política del alcohol. Resulta, sin embargo, interesante destacar que en el año 2000, el nivel de impuestos sobre el consumo de alcohol todavía sigue la vieja distinción realizada sobre la base de la bebida preferente. Concretamente, las tasas impositivas sobre el alcohol son claramente menores en los países mediterráneos consumidores de vino, así como en otros países productores de vino. Entre los países ECAS, los impuestos sobre el alcohol son más elevados en los países nórdicos, i.e. los antiguos consumidores de licores, seguidos de Dinamarca, Irlanda y el Reino Unido. Los países ECAS que se hallan entre ambos extremos están situados en el centro de la Europa Continental. Ni siquiera por lo que se refiere al nivel de los impuestos sobre el alcohol, los países centroeuropeos consumidores de cerveza constituyen un grupo demasiado homogéneo, tal como puede observarse al comparar el nivel de las tasas impositivas sobre el alcohol en Austria y Alemania con las de Irlanda y el Reino Unido. Los datos disponibles no dan una imagen muy clara de las corrientes existentes en los sistemas tributarios especiales sobre el alcohol de los países ECAS en el período 1950-2000. Ello se debe en parte al hecho de que en muchos países ECAS, las 
tasas impositivas sobre el alcohol se cambiaban una vez cada década más que una vez al año.

Resulta evidente que el control sobre la producción y la venta al por mayor del alcohol, aunque también el control de la venta al por menor, ha disminuido. En otras palabras, las políticas del alcohol dirigidas estrictamente a controlar la accesibilidad del alcohol han perdido terreno. La principal explicación de este proceso sería la importancia cada vez mayor del mercado libre, así como el aumento del consumismo. La tendencia cada vez mayor al mercado libre es ostensible en el desarrollo de la Unión Europea, con la creación del mercado único europeo en 1993, que hace hincapié en el movimiento libre de capitales, bienes, servicios y mano de obra, incluyendo la supresión de fronteras para la empresa y el comercio libre. La creación de un mercado único europeo ha llevado a muchos países a abolir numerosas medidas de control del alcohol, desde la producción, la importación, la exportación y los monopolios sobre la venta al por mayor, hasta las nuevas regulaciones sobre licencias para vender bebidas alcohólicas al público. En la mayoría de los países ECAS, la política de licencias es actualmente un trámite formal en el que todos los solicitantes que cumplen una serie de requisitos básicos, por ejemplo no tener antecedentes penales, consiguen el permiso. El principio del mercado libre no parece dejar demasiado espacio a las restricciones especiales sobre la accesibilidad del alcohol motivadas por consideraciones de salud pública o política social.

Cabría esperar que el aumento en el consumo del alcohol de los países ECAS desde los primeros años de la década de 1950 hasta mediados de la década de 1970 condujera a un control más estricto sobre la accesibilidad del alcohol, ya que, desde la perspectiva de la política sanitaria pública, las bebidas alcohólicas no eran de forma categórica productos ordinarios. Contienen alcohol etílico y su consumo puede tener efectos muy perjudiciales para el propio bebedor, su familia y amigos, su comunidad y el conjunto de la sociedad. Sin embargo, desde el punto de vista de la industria y del comercio del alcohol, estas bebidas son productos ordinarios ya que tienen, como el vino, estrechos vínculos con la agricultura. Por ese motivo, no es de extrañar que existan también actores en el campo del alcohol interesados en aumentar la accesibilidad y el consumo del alcohol, que hagan caso omiso de la relación positiva entre el consumo total de este producto y los problemas vinculados al alcohol, e incluso de la pesada carga que supone el alcohol para la sociedad. Por consiguiente, no es infrecuente ver políticas gubernamentales contradictorias en relación con las bebidas alcohólicas. Los ministerios de Agricultura intentan a menudo salvaguardar los intereses de los viticultores, e incluso tratan de promocionar el mercado del vino. Los ministerios de Industria, por otra parte, actúan en interés de las fábricas de cerveza y de las destilerías, mientras que los ministerios de Asuntos Sociales y de Sanidad intentan promover políticas que disminuyan los daños ocasionados por el alcohol, y tal vez incluso limitar el consumo total de este producto. Este conflicto de intereses en relación con la política del alcohol y el equilibrio de poder entre ellos han influido en el desarrollo de la accesibilidad del alcohol en los países ECAS durante el período 1950-2000.

Asimismo, el aumento del consumismo ha supuesto una mayor presión sobre las medidas de control del alcohol, ya que los consumidores no desean continuar siendo dirigidos por el estado (Sulkunen y col., 2000). Por esa razón, las restricciones en los días y en las horas de venta de bebidas alcohólicas al público, así como otros obstáculos para limitar la libertad de elección del consumidor, han sido cada vez más criticadas por los consumidores de alcohol, hasta el punto de que muchas de estas restricciones se han suavizado o han sido suprimidas. El límite de edad legal para comprar bebidas alcohólicas, sin embargo, se ha mantenido, e incluso se ha hecho más estricto a lo largo de la segunda mitad del siglo XX. Ello refleja los cambios en el hábito de la bebida entre los adolescentes, y la disminución del control social extraoficial del consumo de alcohol. Además, los daños vinculados al consumo de alcohol entre los jóvenes resultan ostensibles y, por tanto, un blanco fácil para unas medidas más rigurosas de control en el consumo de alcohol.

Otras áreas que han ganado claramente importancia son el control social y ambiental y el control de marketing de las bebidas alcohólicas. En la práctica, eso significa que en nuestros días hay más medidas de control, y más rigurosas, ante determinados problemas relacionados con el alcohol, por ejemplo la conducción de vehículos en estado de embriaguez; y también ante su consumo público tanto a nivel general como en ciertas situaciones en las que tienden a aparecer problemas. La imposición o reducción de los límites BAC para conducir un vehículo reflejan sin duda el aumento de los problemas relacionados con el alcohol, ya que no sólo ha aumentado la intensidad del tráfico en los últimos cincuenta años, sino también el consumo de alcohol. En algunos informes nacionales se llega incluso a reivindicar que el control de la conducción en estado de embriaguez mediante unos límites BAC más bajos ha reducido el consumo de alcohol en los locales donde se vende este producto para consumir en su interior, o al menos eso teme la industria del alcohol (ver e.g., Hope y col., 2001). También existen en nuestros días otras medidas que buscan influir en la demanda de las bebidas alcohólicas, incrementando la información y la educación sobre el alcohol e introduciendo una regulación nueva 
y más rigurosa en la publicidad y en la esponsorización del alcohol.

En la actualidad, la mayoría de los países ECAS tienen un programa nacional de educación o de prevención del alcohol, o un organismo encargado del tema. Incluso en los países donde no existen esa clase de programas, por ejemplo Grecia, se ha discutido seriamente si debían ser introducidos. Los programas de prevención y educación no son una garantía de eficacia. Y, sin embargo, su existencia significa que el problema del alcohol se ha incluido, de una u otra forma, en la agenda política nacional, y que los términos "política del alcohol" y "política de control del alcohol" se comprenden mejor en nuestros días. Dicha evolución influye, asimismo, en el análisis y en la planificación de la política futura del alcohol. El hecho de que esa clase de programas sean ahora más frecuentes se debe en parte a las actividades de la Organización Mundial de la Salud, cuyas oficinas europeas han elaborado unos planes de actuación sobre el alcohol con el acuerdo de sus estados miembro, animando a todos éstos a ponerlos en práctica junto con sus recomendaciones.

Las políticas del alcohol son actualmente más similares entre los países ECAS de lo que solían ser a principios de la década de 1950. Detrás de las tendencias convergentes entre los países ECAS, podemos encontrar, básicamente, dos evoluciones diferentes:

Las medidas que afectan la accesibilidad del alcohol se aplican hoy en día en mucho menor grado que hace cincuenta años. En otras palabras, los países que en la década de 1950 tenían unas medidas muy estrictas de control del alcohol las han desmantelado, mientras que los países que han comenzado a interesarse en una política del alcohol, no han centrado su atención en controlar la accesibilidad de dicho producto.

Las medidas de control del alcohol dirigidas a determinados problemas relacionados con su consumo y que pretendían influir en la demanda de bebidas alcohólicas se han hecho más comunes en todos los países ECAS, y las cuestiones vinculadas a la política del alcohol están actualmente, en mayor o menor medida, en la agenda política de la mayoría de los países ECAS.

\section{POLÍTICAS DEL ALCOHOL EN LOS PAÍSES ECAS - PRONÓSTICOS DE FUTURO}

En la mayoría de los países ECAS, el nivel de consumo de alcohol per capita era más elevado en el año 2000 que en el año 1950 (Leifman, 2001; World Drink Trends, 2000). Especialmente, el período comprendido entre el final de la Segunda Guerra Mundial y mediados de la década de 1970 se caracterizó por un crecimiento del consumo total de alcohol. Desde mediados de la década de 1970, el consumo total de alcohol descendió en los países ECAS consumidores de vino, mientras que continuó siendo estable en la mayoría de los restantes países ECAS (si bien aumentó en algunos de ellos).

Existe una clara relación entre el consumo total de alcohol per capita y los problemas relacionados con el alcohol, tal como fue documentado en numerosos estudios e investigaciones antes de que el proyecto ECAS lo confirmara (ver e.g., Bruñí y col., 1975; Edwards y col., 1994). También se ha demostrado que las medidas de control del alcohol que tienen que ver con la accesibilidad de las bebidas alcohólicas influyen generalmente en el consumo total de alcohol (ver e.g., Edwards y col., 1994). Es evidente que cambiar los precios del alcohol afecta al consumo de alcohol (ver e.g., Österberg, 2001; Leppänen, Sullström \& Suoniemi, 2001). Muchos de los estudios más convincentes sobre la relación entre los cambios en la accesibilidad del alcohol y el consumo total de alcohol provienen de los países anglosajones o de la Unión Europea, especialmente de los países nórdicos (ver e.g., Österberg, 1991; Stockwell \& Gruenewald, 2001). No está tan claro que las medidas que afectan la demanda de bebidas alcohólicas sean efectivas (ver e.g., Edwards y col., 1994).

La relación entre el aumento del consumo total de alcohol y el incremento de los problemas relacionados con el alcohol no es directa. Variar los hábitos de bebida u otros cambios sociales pueden influir en esta relación. Por consiguiente, el aumento del consumo total de alcohol puede no conducir al incremento de los problemas relacionados con el alcohol, ni a una necesidad mayor de tomar medidas de control del alcohol. Esta posibilidad no parece, sin embargo, responder a la realidad de los países ECAS en las últimas cinco décadas. En contra de la situación anteriormente descrita, podría sorprender la existencia de una tendencia general en los países ECAS a suprimir las medidas de control del alcohol relacionadas con la accesibilidad del alcohol y que han demostrado ser eficaces, y a introducir al mismo tiempo unas medidas de control dirigidas a influir en la demanda del alcohol, incluso sabiendo que son menos efectivas, al menos a corto plazo.

Garantizar el movimiento libre de capitales, bienes, servicios y mano de obra ha sido el principio fundamental a la hora de organizar la economía mundial en las últimas décadas, y ha eclipsado la necesidad de controlar el consumo total de alcohol, tanto por cuestiones de sanidad pública como de orden público. Eso explicaría para nosotros la tendencia general hacia la abolición de las medidas de control del alcohol relacionadas con la accesibilidad del alcohol. Muchas de estas medidas han sido consideradas (como lo seguirán siendo las que aún quedan) obstáculos para el comercio libre de las bebidas alcohólicas. Es difícil 
saber si esta tendencia será discontinua o cambiará, incluso cuando, por ejemplo, las consideraciones sobre la sanidad pública y la política social han cobrado mayor importancia en los países de la Unión Europea durante la última década (ver e.g., Sutton \& Nylander, 1999; Österberg \& Karlsson, 2001c). En cualquier caso, resultaría casi imposible que estructuras como el sistema general de monopolio sobre el alcohol, eficaces en los países nórdicos hace menos de una década, pudieran restablecerse en el futuro en cualquiera de los países de la Unión Europea.

Los consumidores de alcohol suelen ver esta clase de bebidas como un producto ordinario que satisface, en muchos sentidos, sus necesidades individuales. De otro modo, sería difícil comprender por qué motivo están tan dispuestos a gastar buena parte de su dinero en comprar bebidas alcohólicas, aun siendo conscientes de sus posibles efectos perjudiciales, gracias a la bien distribuida información sobre el alcohol. Eso significa que es muy difícil legitimar medidas que limiten la accesibilidad del alcohol aludiendo a sus efectos perjudiciales, si los principales consumidores consideran, con o sin razón, que son capaces de controlar la bebida y que no necesitan ni aceptan ser dirigidos directamente por el estado. Creemos que esta clase de situación continuará en los países ECAS incluso en el futuro. $Y$, finalmente, no existe el menor indicio de que la industria del alcohol y del comercio vaya a tomar en el futuro una postura más favorable que en la actualidad hacia las restricciones en la accesibilidad del alcohol. En resumen, podría pronosticarse que las medidas de control del alcohol destinadas a afectar la accesibilidad del alcohol y dirigidas al aspecto del suministro en la ecuación del alcohol serán, por lo general, más escasas y menos rigurosas en el futuro.

Los posibles daños derivados del consumo de bebidas alcohólicas no parecen estar desapareciendo en los países ECAS, y no sólo afectan al propio bebedor. A menudo terceras personas, como familiares, amigos o miembros de la misma comunidad, padecen las consecuencias. Por ese motivo, es bastante frecuente que el entorno del bebedor intente reducir su consumo de alcohol mediante un control social informal, que puede traducirse en un control personal directo o en unas normas sociales y culturales, más o menos desarrolladas, sobre dónde, cuándo y cómo debería o no debería beberse alcohol. En algunos países, ese modo tradicional de hacer frente a los problemas relacionados con el alcohol ha dejado de funcionar como antes. Puesto que el control social informal del alcohol está perdiendo terreno, es posible que en el futuro veamos medidas de control nuevas y más formales que intenten limitar el consumo de alcohol en los lugares de trabajo, en los establecimientos educativos o de atención pública, en las oficinas gubernamentales, en el transporte público y en los acontecimientos deportivos o recreativos, así como en los parques y en las calles.

Quizá esta tendencia se extienda también a las medidas destinadas a influir en determinados grupos de consumidores de alcohol, y se aumente, por ejemplo, el límite de edad para controlar el consumo de los adolescentes, la información sobre el alcohol para las mujeres embarazadas, los intentos para prevenir que los borrachos ya conocidos compren alcohol; y se endurezcan, asimismo, los controles del consumo de alcohol en los estadios deportivos y en otras situaciones que corran el peligro de convertirse en problemáticas, y se aumente la responsabilidad legal de los establecimientos que venden bebidas alcohólicas para consumir en su interior por la conducta de sus clientes. Las tendencias que han podido observarse en los países ECAS en la segunda mitad del siglo XX pueden también conducir al incremento de las actividades que traten de influir directamente sobre determinados problemas relacionados con el alcohol, como, por ejemplo, la conducción de vehículos en estado de embriaguez. Los límites legales BAC con toda seguridad seguirán disminuyendo, y es posible que en el futuro se dividan en dos categorías diferentes de conductores, estableciéndose, por ejemplo, límites más bajos para jóvenes y conductores profesionales. Por otra parte, si el consumo de alcohol y los problemas relacionados con dicho producto se mantienen al nivel actual o empiezan a crecer, veremos ciertamente cómo se ponen en marcha más campañas de información y más programas educativos, y cómo se endurece el control sobre la publicidad y la esponsorización de las bebidas alcohólicas.

Si no queda lugar, en un mundo dominado por el mercado libre, para limitar el acceso al alcohol, y si la regulación de la demanda de bebidas alcohólicas no es una estrategia suficientemente eficaz para combatir los problemas relacionados con el alcohol, existen en principio otras dos posibilidades para controlar dichos problemas. La primera de ellas sería intentar definir, encontrar y separar a los alcohólicos, bebedores problemáticos o individuos que beben demasiado, e intentar curarlos, educarlos, persuadirlos u obligarlos a beber menos, abandonar por completo la bebida o cambiar sus hábitos de consumo. La segunda, utilizar los impuestos sobre el alcohol como un instrumento de la política preventiva del alcohol. La primera opción, así como la información general sobre el alcohol, resulta muy conveniente para la población de bebedores y para la industria y el comercio del alcohol, ya que apenas afecta al consumo, a la producción y al comercio, pero es muy costosa para los gobiernos y, en última instancia, para los contribuyentes. La última opción es políticamente difícil, aunque desde el punto de vista del estado o de las autoridades locales resultaría muy barata; de hecho, sería un modo muy sencillo de recaudar más impuestos. 


\section{BIBLIOGRAFÍA}

Agreement SOC 98200739 05F03 (98CVVF3-420-0). European Commission, Directorate-General V, Employment, Industrial Relations and Social Affairs.

Alavaikko, M. \& Österberg, E. (2000) The influence of economic interests on alcohol control policy: a case study from Finland. Addiction, 95 (Supplement 4), S565S579.

Allamani, A., Cipriani, F., Voller, F., Rossi, D., Anav, S., Karlsson, T. \& Österberg, E. (2001) Italy, in: Österberg, E. \& Karlsson, T. (Eds.) Alcohol Policies in EU Member States and Norway (Helsinki, Stakes).

Britton, A., Karlsson, T. \& Österberg, E. (2001) The United Kingdom, in: Österberg, E. \& Karlsson, T. (Eds.) Alcohol Policies in EU Member States and Norway (Helsinki, Stakes).

Bruun, K., Edwards, G., Lumio, M., Mäkelä, K., Pan, L., Popham, R. E., Room, R., Schmidt, W., Skog, O.-J., Sulkunen, P. \& Österberg, E. (1975) Alcohol control policies in public health perspective. A collaborative project of the Finnish Foundation for Alcohol Studies, the World Health Organization Regional Office for Europe \& The Addiction Research Foundation of Ontario ( Helsinki, Finnish Foundation for Alcohol Studies).

Davies P. \& Walsh B. (1983) Alcohol Problems and Alcohol Control in Europe (London \& Canberra, Croom Helm).

Edwards, G., Anderson, P., Babor, T. F., Casswell, S., Ferrence, R., Giesbrecht, N., Godfrey, C., Holder, H., Lemmens, D. P., Mäkelä, K., Midanik, L., Norström, T., Österberg, E., Romelsjö, A., Room, R., Simpura, J. \& Skog, O.-J. (1994) Alcohol Policy and the Public Good (Oxford, Oxford University Press).

Eisenbach-Stangl, I., Uhl, A., Karlsson, T. \& Österberg, E. (2001) Austria, in: Österberg, E. \& Karlsson, T. (Eds.) Alcohol Policies in EU Member States and Norway (Helsinki, Stakes).

Gefou-Madianou, D in collaboration with Karlsson, T. \& Österberg, E. (2001) Greece, in: Österberg, E. \& Karlsson, T. (Eds.) Alcohol Policies in EU Member States and Norway (Helsinki, Stakes).

Holder, H. D., Kühlhorn, E., Nordlund, S., Österberg, E., Romelsjö, A. \& Ugland, T. (1998) European Integration and Nordic Alcohol Policies. Changes in alcohol control policies and consequences in Finland, Norway and Sweden, 1980-1997 (Aldershot, Ashgate Publishing Ltd).

Hope, A., Byrne, S., Karlsson, T. \& Österberg, E. (2001) Ireland, in: Österberg, E. \& Karlsson, T. (Eds.) Alcohol Policies in EU Member States and Norway (Helsinki, Stakes).

Karlsson, T. \& Österberg, E. (2001a) A scale of formal alcohol control policy in 15 European Countries, Nordisk alkohol- \& narkotikatidskrift, Nordic Studies on Alcohol and Drugs, 18 (English Supplement), 117-131.
Karlsson, T. \& Österberg, E. (2001b) Belgium, in: Österberg, E. \& Karlsson, T. (Eds.) Alcohol Policies in EU Member States and Norway (Helsinki, Stakes).

Karlsson, T. \& Österberg, E. (2001c) Finland, in: Österberg, E. \& Karlsson, T. (Eds.) Alcohol Policies in EU Member States and Norway (Helsinki, Stakes).

Karlsson, T. \& Österberg, E. (2001d) France, in: Österberg, E. \& Karlsson, T. (Eds.) Alcohol Policies in EU Member States and Norway (Helsinki, Stakes)

Karlsson, T. \& Österberg, E. (2001e) The Netherlands, in: Österberg, E. \& Karlsson, T. (Eds.) Alcohol Policies in EU Member States and Norway (Helsinki, Stakes).

Karlsson, T. \& Österberg, E. (2001f) Norway, in: Österberg, E. \& Karlsson, T. (Eds.) Alcohol Policies in EU Member States and Norway (Helsinki, Stakes).

Karlsson, T. \& Österberg, E. (2001g) Portugal, in: Österberg, E. \& Karlsson, T. (Eds.) Alcohol Policies in EU Member States and Norway (Helsinki, Stakes).

Karlsson, T. \& Österberg, E. (2001h) Spain, in: Österberg, E. \& Karlsson, T. (Eds.) Alcohol Policies in EU Member States and Norway (Helsinki, Stakes).

Karlsson, T. \& Österberg, E. (2001i) Sweden, in: Österberg, E. \& Karlsson, T. (Eds.) Alcohol Policies in EU Member States and Norway (Helsinki, Stakes).

Karlsson, T. \& Simpura, J. (2001) Changes in living conditions and their links to alcohol consumption and drinking patterns in 16 European countries, 1950 to 2000, Nordisk alkohol- \& narkotikatidskrift, Nordic Studies on Alcohol and Drugs, 18 (English Supplement), 82-99.

Kümmler, P., Jünger, S., Kraus, L., Karlsson, T. \& Österberg, E. (2001) Germany, in: Österberg, E. \& Karlsson, T. (Eds.) Alcohol Policies in EU Member States and Norway (Helsinki, Stakes).

Leifman, H. (2001) Homogenisation in alcohol consumption in the European Union, Nordisk alkohol- \& narkotikatidskrift, Nordic Studies on Alcohol and Drugs, 18 (English Supplement), 15-30.

Leppänen, K., Sullström, R. \& Suoniemi, I. (2001) The Consumption of Alcohol in Fourteen European Countries. A Comparative Econometric Analysis (Helsinki, Stakes).

Österberg, E. (1987) Alcohol and traffic in Finland, Accident Analysis and Prevention, 19, 463-473.

Österberg, E. (1989) Country Profiles: Finland, in: Kortteinen, T. (Ed.) State Monopolies and Alcohol Prevention, Report and Working Papers of a Collaborative International Study, Report No. 181, pp. 107-156 (Helsinki, Social Research Institute of Alcohol Studies).

Österberg E. (1991) Current approaches to limit alcohol abuse and the negative consequences of use: $A$ comparative overview of available options and an assessment of proven effectiveness, pp. 266-299, Expert meeting on the Negative Social Consequences of Alcohol Use, Oslo, 27-31 August 1990 (Oslo, Norwegian Ministry of Health and Social Affairs)

Österberg, E. (2001) Effects of price and taxation, in: Heather, N., Peters, T. J. \& Stockwell, T. (Eds.) International 
Handbook of Alcohol Dependence and Problems, pp. 685-698 (Chichester, U.K., John Wiley \& Sons, Ltd). Österberg, E. \& Karlsson, T. (2001a) (Eds.) Alcohol Policies in EU Member States and Norway (Helsinki, Stakes).

Österberg, E. \& Karlsson, T. (2001b) Studying alcohol policies in national and historical perspectives, in: Österberg, E. \& Karlsson, T. (Eds.) Alcohol Policies in EU Member States and Norway (Helsinki, Stakes).

Österberg, E. \& Karlsson, T. (2001c) Trends in alcohol policies in the ECAS countries, 1950-2000, in: Österberg, E. \& Karlsson, T. (Eds.) Alcohol Policies in EU Member States and Norway (Helsinki, Stakes).

Österberg, E. \& Karlsson, T. (2001d) Alcohol policy at the European Union level, in: Österberg, E. \& Karlsson, T. (Eds.) Alcohol Policies in EU Member States and Norway (Helsinki, Stakes).

Stockwell, T. \& Gruenewald, P. (2001) Controls on the physical availability of alcohol, in: Heather, N., Peters, T. J. \& Stockwell, T. (Eds.) International Handbook of Alco- hol Dependence and Problems, pp. 699-719 (Chichester, U.K., John Wiley \& Sons, Ltd).

Sulkunen, P., Sutton, C., Tigerstedt, C. \& Warpenius, K. (Eds.) (2000) Broken Spirits. Power and Ideas in Nordic Alcohol Control. NAD Publication No. 39 (Helsinki, Hakapaino Oy).

Sutton, C. \& Nylander, J. (1999) Alcohol policy strategies and public health policy at an EU-level. The case of alcopops, Nordisk alkohol- \& narkotikatidskrift, Nordic Studies on Alcohol and Drugs, 16 (English Supplement), 74-91.

Thorsen, T., Karlsson, T. \& Österberg, E. (2001) Denmark, in: Österberg, E. \& Karlsson, T. (Eds.) Alcohol Policies in EU Member States and Norway (Helsinki, Stakes).

World Drink Trends (2000) International Beverage Consumption and Production Trends. Productschap voor Gedistilleerde Dranken (Oxfordshire, United Kingdom, NTC Publications Ltd). 
